ISSN = 1980-993X - doi:10.4136/1980-993X
www.agro.unitau.br/ambi-agua
E-mail: ambi-agua@agro.unitau.br
Tel.: (12) 3625-4116

\title{
Desempenho agronômico de capim tifton 85 (cynodon spp) cultivado em sistemas alagados construídos utilizados no tratamento de água residuária de laticínios \\ (doi:10.4136/ambi-agua.41)
}

\author{
Antonio Teixeira de Matos"; Sérgio Silva Abrahão²; Odilon Gomes Pereira ${ }^{3}$ \\ ${ }^{1}$ Engenheiro Agrícola, D.S., Professor do Departamento de Engenharia Agrícola, Universidade Federal de \\ Viçosa, bolsista do CNPq \\ E-mail: atmatos@ufv.br \\ ${ }^{2}$ Engenheiro Agrícola, M.Sc. em Engenharia Agrícola, Departamento de Engenharia Agrícola, UFV \\ E-mail: sergio@ctazm.org.br \\ ${ }^{3}$ Agrônomo, D.S., Professor do Departamento de Zootecnia, Universidade Federal de Viçosa, UFV \\ E-mail: odilon@ufv.br
}

\section{RESUMO}

O objetivo, com a realização deste trabalho, foi estudar o desempenho do capim tifton 85 (Cynodon spp), cultivado em Sistemas Alagados Construídos (SACs) e submetido a diferentes taxas de aplicação de carga orgânica (TCOs), proporcionadas pela aplicação de misturas de águas residuárias da indústria de laticínios (ARL) com água, nas condições climáticas de Viçosa, MG. A infra-estrutura experimental foi constituída por cinco SACs com fluxo subsuperficial horizontal: tanques de 0,40 × $0,75 \times 3,00 \mathrm{~m}$ (profundidade, largura e comprimento), impermeabilizados e preenchidos com $0,33 \mathrm{~m}$ de profundidade de brita zero. A ARL foi aplicada numa vazão média de $60 \mathrm{~L}^{-1 i a^{-1}}$ e tempo de residência hidráulica de 4,8 dias e TCOs de 66, 130, 190, 320 e $570 \mathrm{~kg} \mathrm{ha}^{-1}$. dia $^{-1}$ de DBO. O capim tifton 85 se adaptou bem aos SACs, apresentando bom enraizamento, alta produtividade e grande capacidade de remover nutrientes ( $\mathrm{N}, \mathrm{P}$ e K) e sódio da ARL, cujos valores estiveram, respectivamente, entre 216 e 544, 24 e 61, 115 e 204 e 4,3 e 10,9 kg.ha ${ }^{-1}$.

Palavras-chave: águas residuárias; leitos cultivados; processamento do leite.

\section{Agronomic performance of tifton 85 (cynodon spp) grass cultivated in constructed wetlands used in milk processing wastewater treatment}

\begin{abstract}
The present work was carried out in order to study the performance of the tifton 85 (Cynodon spp) grass cultivated in wetlands (SACs) and submitted to different organic load application rates (TCOs) of milk processing wastewater (ARL), in the climatic conditions of Viçosa MG. The experimental structure was constituted by five SACs with horizontal subsuperficial flow, using tanks of $0.40 \times 0.75 \times 3.00 \mathrm{~m}$ (depth, width and length) filled with $0.33 \mathrm{~m}$ depth of fine stones. The ARL was applied in average flow of $60 \mathrm{~L}^{-d_{a y}{ }^{-1}}$, hydraulic time residence of 4.8 days and TCOs of 66, 130, 190, 320 and $570 \mathrm{~kg} \mathrm{ha}^{-1}$.day ${ }^{-1}$ of DBO. The tifton 85 grass adapted well to SACs, presenting good rooting ${ }_{2}$ high yield and capacity of nutrients (N, P and K) and sodium removal of the ARL, whose values were, respectively, between 216 - 544, 24 61, 115 - 204 and $4.3-10.9$ kg.ha ${ }^{-1}$.
\end{abstract}

Keywords: wastewater; wetland; milk processing. 


\section{INTRODUÇÃO}

Nas últimas décadas, tem sido crescente o interesse por Sistemas Alagados Construídos (SACs), por se tratar de tecnologia simples, de baixo custo, fácil operação e manutenção para o tratamento de grande diversidade de produtos líquidos, ricos em material orgânico susceptível à biodegradação (Brasil et al., 2007). Esses sistemas oferecem benefícios ambientais consideráveis, tais como sua integração a parques e sistemas recreacionais, possibilitando o desenvolvimento de animais silvestres, harmonizando-se com a paisagem natural e proporcionando a produção de efluentes de boa qualidade, que poderão ser utilizados para outros fins ou lançados em corpos hídricos receptores.

Os SACs são sistemas projetados para utilizar plantas cultivadas em substratos (solo, areia, brita ou cascalho), onde, naturalmente, sob condições ambientais adequadas, ocorrem processos físicos, químicos e bioquímicos de tratamento das águas residuárias. Segundo Paganini (1997), as espécies vegetais a serem selecionadas devem ser perenes, ter alta tolerância ao excesso de água e a ambientes eutrofizados, ser de fácil propagação e crescimento rápido, ser de fácil colheita e manejo e possuir alta capacidade de remoção de nutrientes e poluentes. Além disso, devem apresentar denso sistema radicular, ser pouco susceptível a pragas e doenças e ser passível de cortes sucessivos e freqüentes.

A escolha deve incluir espécies com grande capacidade de extração de nutrientes, que se desenvolvam bem em ambientes encharcados, com rusticidade suficiente e alto poder de dominação (capacidade de se sobressair em relação a outras plantas), além de apresentar valor nutricional para alimentação animal.

Grande número de espécies vegetais, quase que exclusivamente aquáticas, têm sido cultivadas em SACs, no Brasil, sendo utilizadas as seguintes macrófitas: Juncus sp. (Sousa et al., 2000), Echimochloa polytachya (Sezerino e Philippi, 2003), Typha sp. (Hussar, 2001; Campos et al., 2002; Valentim, 2003; Brasil et al., 2005), Zizaniopsis bonariensis (Campos et al., 2002), Eleocharis sp. e Scirpus sp. (Valentim, 2003) e arroz (Oriza sativa L.) (Nogueira, 2003). Entretanto, pouco ainda se sabe sobre quais seriam as espécies mais indicadas e como deveria ser o seu manejo, qual o desempenho dos sistemas e o potencial para remoção de diferentes compostos, no tratamento de diferentes águas residuárias em SACs.

O capim tifton 85, uma das espécies do gênero Cynodon, possui boas características de produção e elevada capacidade de crescimento, apresentando grande potencial de uso como forrageira nas condições subtropicais e tropicais. Seu relvado atinge até $1 \mathrm{~m}$ de altura e é forrageira resistente a cortes freqüentes. A matéria seca produzida, em boas condições de manejo e adubação, é de boa qualidade, permitindo bom desempenho animal na produção de leite e carne. Muito embora tenham sido realizados poucos trabalhos de pesquisa com essa gramínea no Brasil, ela tem demonstrado um bom desempenho, quando avaliada (Cecato e Bortolo, 1999).

Stefanutti et al. (1999) avaliaram o comportamento do capim tifton 85 em rampas de tratamento de esgoto doméstico e consideraram esse capim eficiente na remoção de nutrientes aplicados no solo, considerando-o apropriado para cultivo nesses sistemas de tratamento, por apresentar fechamento homogêneo e mais denso, além de apresentar recuperação mais rápida após o corte.

Queiroz et al. (2004), estudando o desempenho de quatro espécies forrageiras (capim quicuio da Amazônia, capim braquiária, capim coastcross e capim tifton 85) cultivadas em rampas e submetidas à aplicação de água residuária da suinocultura, pelo método do escoamento superficial, verificaram que, dentre as gramíneas forrageiras avaliadas, o capim tifton 85 foi o que se mostrou mais adequado para cultivo em rampas de tratamento de águas 
residuárias da suinocultura por escoamento superficial devido à alta produtividade e capacidade de extração de nutrientes alcançadas, além da rápida recuperação após o corte, com boa cobertura do solo e o impedimento ao desenvolvimento de poucas espécies invasoras no local.

Por existir pouca informação sobre o desempenho agronômico de espécies de vegetais quando cultivadas em SACs, em diferentes taxas de carga orgânica, no presente trabalho tevese como objetivo estudar o desempenho de Sistemas Alagados Construídos, cultivados com capim tifton 85 (Cynodon spp), submetidos a diferentes taxas de aplicação de carga orgânica proporcionadas pela aplicação de águas residuárias da indústria de laticínios (ARL), nas condições climáticas de Viçosa, MG.

\section{MATERIAL E MÉTODOS}

O experimento foi conduzido na Área Experimental de Hidráulica, Irrigação e Drenagem do Departamento de Engenharia Agrícola da UFV, em Viçosa, MG. Para a realização dos estudos, foram utilizadas águas residuárias brutas provenientes da Usina de Beneficiamento de Leite da Fundação Arthur Bernardes (Laticínios da FUNARBE), localizada no Campus da UFV.

A infra-estrutura experimental foi constituída por cinco leitos de sistemas alagados construídos (SACs) com fluxo subsuperficial horizontal. Cada SAC foi constituído por um tanque de $0,40 \times 0,75 \times 3,00 \mathrm{~m}$ (profundidade, largura e comprimento), impermeabilizado, preenchido com substrato de brita zero, declividade de base de $0,5 \%$ no sentido longitudinal do tanque e profundidade do leito filtrante de 0,33 m.

Para facilitar o pegamento das mudas de capim, os SACs foram previamente saturados com água residuária proveniente da suinocultura da UFV, posteriormente foi feito o plantio, utilizando-se propágulos vegetativos (rizomas+caule) com, aproximadamente, 0,30 m de comprimento. A densidade de plantio foi, em média, 14 propágulos. $\mathrm{m}^{-2}$ e o plantio ocorreu em apenas uma etapa, no dia 16 de abril de 2005.

Após o plantio dos propágulos, deu-se continuidade ao fornecimento da água residuária proveniente da suinocultura nos SACs com e sem vegetação, com uma freqüência de 3 vezes por semana, até o dia 3 de agosto de 2005. A partir do dia 4 de agosto de 2005, passou-se a aplicar, na mesma freqüência, apenas água "limpa” do manancial (AM) e no dia 19 de agosto de 2005 deu-se a partida de operação nos SACs com aplicação diária da água residuária do laticínio (ARL).

A água residuária afluente aos SACs foi aplicada de forma a se promover o seu escoamento de forma subsuperficial, com vazão média de $60 \mathrm{~L} \cdot \mathrm{dia}^{-1}$ e tempo de residência hidráulica igual a 4,8 dias nos tanques. As taxas de carga orgânicas aplicadas (TCOs) em cada tratamento foram de 66, 130, 190, 320 e $570 \mathrm{~kg} \cdot \mathrm{ha}^{-1} \cdot \mathrm{dia}^{-1}$ de DBO, denominados respectivamente de CT-66, CT-130, CT-190, CT-320 e CT-570, respectivamente. As diferentes cargas orgânicas dos afluentes foram obtidas por meio de misturas da água residuária de laticínio (ARL) bruta, que tinha DBO de aproximadamente 2.500 mg.L ${ }^{-1}$, com água "limpa" do manancial (AM). Os tratamentos foram aplicados até 9 de dezembro, ocasião em que foi feito o segundo corte do capim e encerrado o experimento.

As principais características físicas, químicas e bioquímicas da água residuária do laticínio (ARL) e da água "limpa" de manancial (AM), utilizadas para a dosagem das TCOs estão apresentadas na Tabela 1. A coleta da biomassa, realizada após ter sido realizado um corte de uniformização dos estandes de plantas, foi efetuada em duas ocasiões diferentes, num intervalo de 45 dias, aproximadamente, sendo constituída pelo corte das plantas de toda área 
de cada SAC, que foi subdividida em três subáreas (início, meio e fim), numa altura entre 5 e $10 \mathrm{~cm}$ acima do meio suporte. Para a quantificação da concentração de nutrientes e sódio no tecido vegetal, amostras do segundo corte do capim tifton 85 foram submetidas à digestão nítrico-perclórico, seguida da quantificação do N-total pelo método semimicro Kjeldahl, do Ptotal por espectrofotometria e $\mathrm{K}$ e $\mathrm{Na}$ por fotometria de chama. O valor do conteúdo de proteína bruta foi obtido por multiplicação da concentração de N-total por 6,25, conforme recomendado por Silva (1998). As análises laboratoriais foram realizadas em conformidade com recomendações de Kiehl (1985), sendo efetuadas nos laboratórios de Solo e Resíduos Sólidos e de Química dos Resíduos do Departamento de Engenharia Agrícola da UFV.

Tabela 1. Características físicas, químicas e bioquímicas da água residuária do laticínio (ARL) e da água "limpa" de manancial (AM) utilizadas para a dosagem das TCOs (média dos valores medidos nas seis amostragens efetuadas).

\begin{tabular}{lccc}
\hline Variáveis & Unidade & \multicolumn{2}{c}{$\begin{array}{c}\text { ARL } \\
\text { Média e Desvio Padrão }\end{array}$} \\
\hline pH & --- & $3,78 \pm 0,47$ & $6,94 \pm 0,17$ \\
CE & $\mu S . \mathrm{cm}^{-1}$ & $994 \pm 110$ & $89 \pm 14$ \\
DBO & $\mathrm{mg} \cdot \mathrm{L}^{-1}$ & $2790 \pm 633$ & $12 \pm 4$ \\
DQO & $\mathrm{mg} \cdot \mathrm{L}^{-1}$ & $5143 \pm 328$ & $20 \pm 6$ \\
SS & $\mathrm{mg} \cdot \mathrm{L}^{-1}$ & $702 \pm 100$ & $3 \pm 3$ \\
$\mathrm{ST}$ & $\mathrm{mg} \cdot \mathrm{L}^{-1}$ & $2407 \pm 442$ & $104 \pm 41$ \\
SD & $\mathrm{mg} \cdot \mathrm{L}^{-1}$ & $1705 \pm 479$ & $101 \pm 43$ \\
$\mathrm{~N}-$ Total & $\mathrm{mg} \cdot \mathrm{L}^{-1}$ & $89,54 \pm 17,3$ & $3,33 \pm 5,7$ \\
P-Total & $\mathrm{mg} \cdot \mathrm{L}^{-1}$ & $22,51 \pm 5,1$ & $0,12 \pm 0,17$ \\
Potássio & $\mathrm{mg} \cdot \mathrm{L}^{-1}$ & $66,36 \pm 23,9$ & $3,77 \pm 1,5$ \\
Sódio & $\mathrm{mg} \cdot \mathrm{L}^{-1}$ & $107,72 \pm 98,4$ & $8,43 \pm 4,2$ \\
\hline
\end{tabular}

No final do período de avaliação dos SACs, foram feitas medidas da profundidade atingida pelas raízes da planta dentro dos SACs.

Os resultados foram interpretados quantitativamente, utilizando-se, para isso, o ajuste de equações matemáticas, escolhidas com base no valor do coeficiente de determinação $\left(\mathrm{R}^{2}\right)$, desde que houvesse lógica para o tipo de comportamento descrito.

\section{RESULTADOS E DISCUSSÃO}

Observou-se que os SACs que receberam maiores TCOs (CT-320 e CT-570) apresentaram menor altura média de planta na zona de entrada e maior na zona de saída (Figura 1a). Contrariamente, os SACs que receberam menores valores de TCO (CT-66 e CT130) apresentaram maior altura média de planta na zona de entrada e menor na zona de saída. O SAC que recebeu TCO intermediária (CT-190) apresentou maior altura média de plantas.

A variação da altura média do capim tifton 85 ao longo dos SACs, em função da TCO aplicada, está, provavelmente, relacionada com o estágio de degradação/decomposição da matéria orgânica ao longo desses tanques. Nos SACs que receberam maiores TCOs, houve maior acúmulo de matéria orgânica na zona de entrada, tornando esta área saturada com esse material, o que constituiu um ambiente francamente redutor e, conseqüentemente, com baixa disponibilidade de nutrientes assimiláveis pelo capim. Nesse caso, admite-se que à medida que o líquido foi se encaminhando para a zona de saída, condições mais oxidantes passaram a ser encontradas e, com isso, maior passou a ser a disponibilidade de nutrientes para as plantas. Já no caso dos SACs que receberam menores taxas de carga orgânica, o aporte de matéria 
orgânica na zona de entrada foi menor e, provavelmente, possibilitou a disponibilização de nutrientes para as plantas em todo o SAC, pelo menos até o período final de monitoramento dos SACs.

Na Figura 1b está ilustrado o aspecto típico da zona radicular do capim tifton 85, desenvolvidas durante o período do experimento, em que se pode observar um desenvolvimento axial e relativamente profundo $(30 \mathrm{~cm})$ das raízes no sistema radicular das plantas, entretanto, verificou-se que a maior densidade de raízes se encontrava concentrada entre a superfície do substrato e a profundidade de $10 \mathrm{~cm}$. As profundidades máximas alcançadas pelas raízes, nesta pesquisa, demonstraram compatibilidade da espessura de 0,30 $\mathrm{m}$ do substrato do meio suporte com o desenvolvimento radicular dessas espécies vegetais.

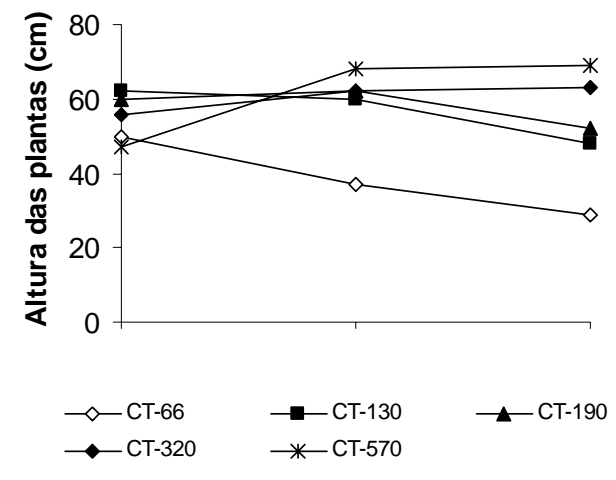

a

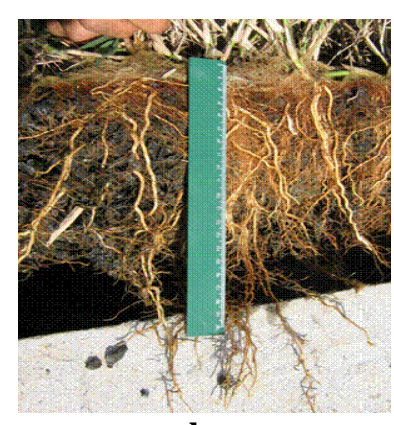

b

Figura 1. Altura média de plantas ao longo do comprimento (início, meio e final) dos SACs, medida 45 dias após a $1^{\text {a }}$ amostragem dos estandes (a), e aspecto típico da zona radicular do capim tifton 85 (b).

As profundidades máximas alcançadas e o tipo de crescimento das raízes principais demonstrou boa adaptação do capim tifton 85 em SACs funcionando em regime de fluxo subsuperficial. O maior desenvolvimento radicular, em profundidade, possibilitando exploração de maior seção molhada dos SACs, é uma característica importante para a seleção de espécies a serem cultivadas em SACs, já que parte importante da absorção de nutrientes (notadamente Ca e Mg) se dá por interceptação radicular (Vargas et al., 1983).

Na Figura 2 está apresentada a curva de produtividade acumulada de matéria seca em função das TCOs, obtida a partir das duas amostragens efetuadas em cada SAC. Ao observar essa Figura, verificou-se que a produtividade de matéria seca aumentou com o acréscimo na TCO aplicada nos SACs. Entretanto, verificou-se, também, tendência de decréscimo na produtividade de matéria seca, quando os valores de TCO se aproximaram de $500 \mathrm{~kg} . \mathrm{ha}^{-1}$.dia ${ }^{-1}$ de DBO. Com base nesses resultados, suspeita-se que a aplicação de TCOs muito superiores a $570 \mathrm{~kg} . \mathrm{ha}^{-1}$.dia ${ }^{-1}$ de DBO poderão prejudicar a produtividade de matéria seca do capim tifton 85, quando cultivado em SACs submetidos a condições semelhantes às de condução deste experimento. 


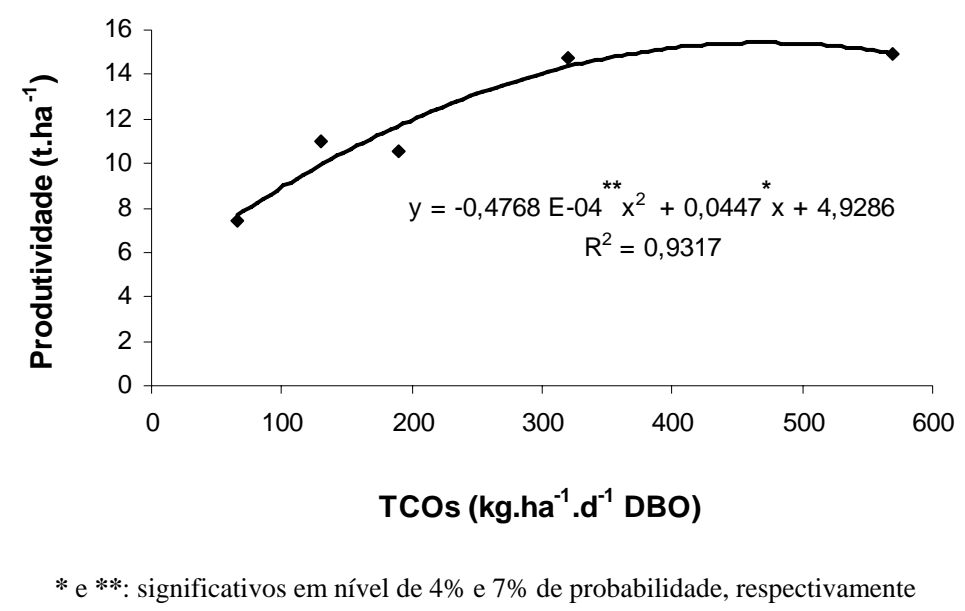

Figura 2. Produtividade acumulada de matéria seca do capim tifton 85, em função das taxas de carga orgânica superficial (TCOs) aplicadas.

Oliveira (1999), em sistema de cultivo convencional (adubação química e irrigação) verificou aumento linear na produtividade de matéria seca do capim tifton 85 , que variou de 3,13 a 12,32 t.ha-1 ${ }^{-1}$ respectivamente, aos 14 e 70 dias após a rebrota. Cultivando da mesma forma, Postiglion e Messias (1998) obtiveram produtividade anual (média de três anos consecutivos), de 10,71 t.ha ${ }^{-1}$ de capim tifton 85. Queiroz et al. (2004) obteve produtividade de 17,7 t.ha $^{-1}$ em tifton 85 fertirrigado com água residuária da suinocultura (aplicação de 800 kg.ha ${ }^{-1} \cdot$ dia $^{-1}$ de DBO). Neste experimento, a produtividade máxima estimada foi de 15,4 t.ha ${ }^{-1}$, obtida com uma TOC de $469 \mathrm{~kg} \cdot \mathrm{ha}^{-1}$. dia ${ }^{-1}$, valor superior ao obtido em cultivos convencionais (adubação química do solo), porém abaixo do obtido por Queiroz et al. (2004) com a aplicação de maior TOC de água residuária da suinocultura, água residuária sabidamente mais rica em nutrientes do que a ARL.

Nas Figuras 3 a 6, estão apresentados os dados experimentais, as curvas e as equações ajustadas de concentração de N, P, K e Na na parte aérea do capim tifton 85 como função da TCO aplicada nos SACs. Verifica-se que houve tendência de aumento na concentração de Ntotal, P-total e $\mathrm{Na}$, na parte aérea do capim tifton 85, com o aumento nas TOCs. Considerando-se relativamente altas as concentrações de sódio no afluente aos SACs e que o potássio sofre a concorrência desse cátion, prejudicando sua absorção pelas plantas, suspeitase que o decréscimo na absorção de potássio possa estar associado, dentre outros fatores, ao aumento na disponibilidade de sódio nos SACs, com o aumento das TCOs aplicadas. Sabe-se que as plantas podem absorver $\mathrm{Na}$ em substituição ao $\mathrm{K}$, para que exerçam funções fisiológicas semelhantes nas plantas. 


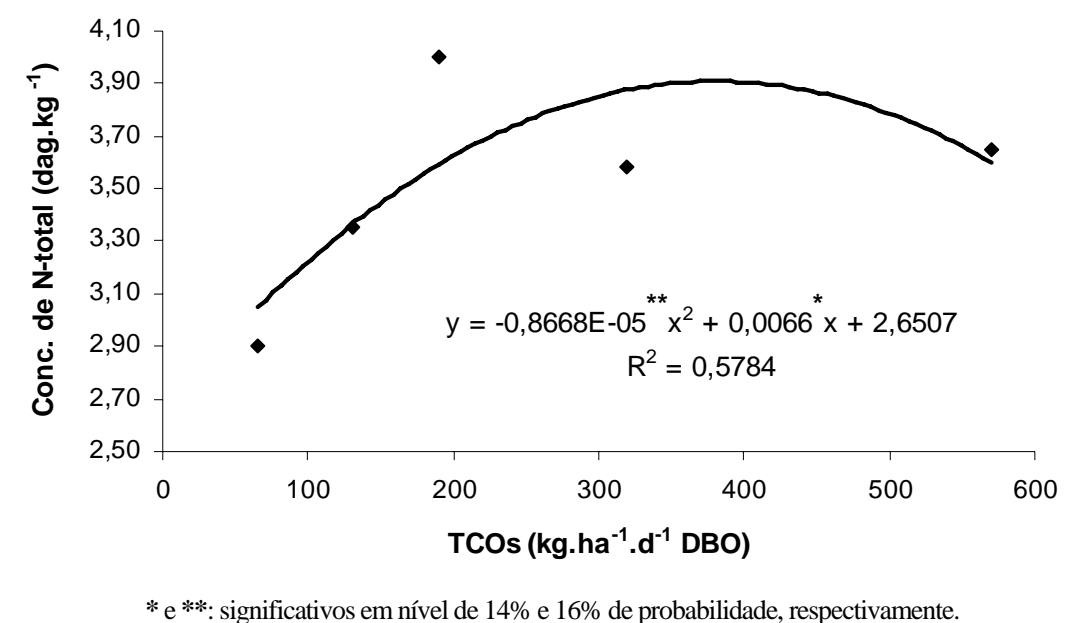

Figura 3. Variação da concentração de N-total na parte aérea do capim tifton 85, em função das taxas de carga orgânica superficial (TCOs) aplicadas.

No que se refere ao nitrogênio, o aumento na concentração ocorreu até TOCs em torno de $400 \mathrm{~kg} \cdot \mathrm{ha}^{-1} \cdot \mathrm{dia}^{-1}$, com ligeira diminuição na concentração desse nutriente a partir dessa taxa. Em relação ao fósforo e o sódio, não foi obtido um ponto de concentração máxima nas faixas de TOCs avaliadas.

A concentração média de P-total foi de 0,36 dag. $\mathrm{kg}^{-1}$. Queiroz (2000), trabalhando com o capim tifton 85 submetido à aplicação de água residuária da suinocultura e água da rede de abastecimento, obteve valores médios de 0,37 e 0,34 dag. $\mathrm{kg}^{-1}$, respectivamente, de concentração de P-total nas folhas.

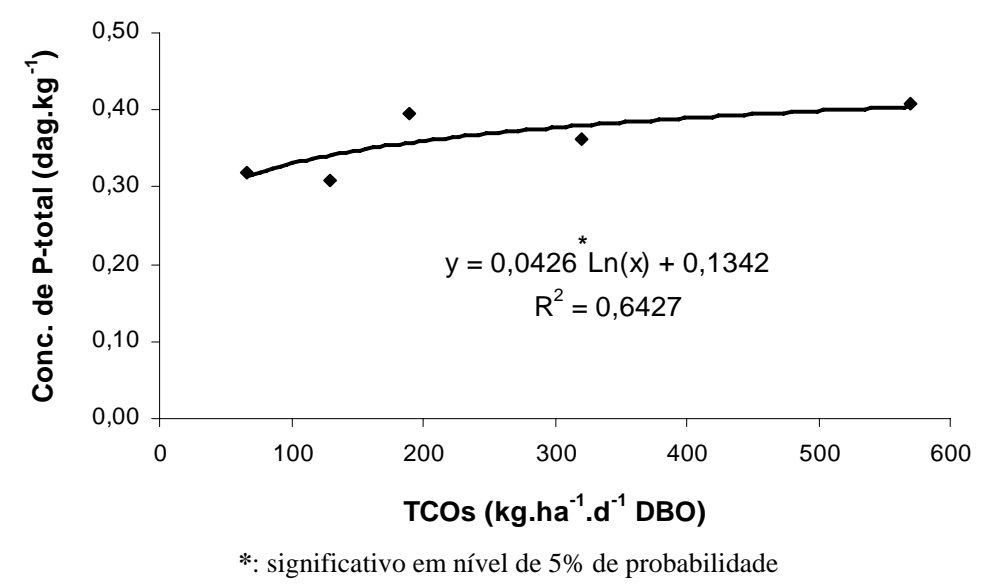

Figura 4. Variação da concentração de P-total na parte aérea do capim tifton 85, em função das taxas de carga orgânica superficial (TCOs) aplicadas.

De acordo com Gomide (1986), a concentração de potássio na faixa de 1,5 a 2,0 dag. $\mathrm{kg}^{-1}$ na parte aérea das plantas pode ser considerada normal para forrageiras e que valores mais elevados indicam absorção de luxo desse nutriente. Com base nisso, pode-se afirmar que o capim tifton 85 tendeu a apresentar concentrações abaixo do normal, tendo sido estimada uma concentração mínima, de 1,3 dag. $\mathrm{kg}^{-1}$, quando foi aplicada uma TOC de $378 \mathrm{~kg} \cdot \mathrm{ha}^{-1}$.dia ${ }^{-1}$. 


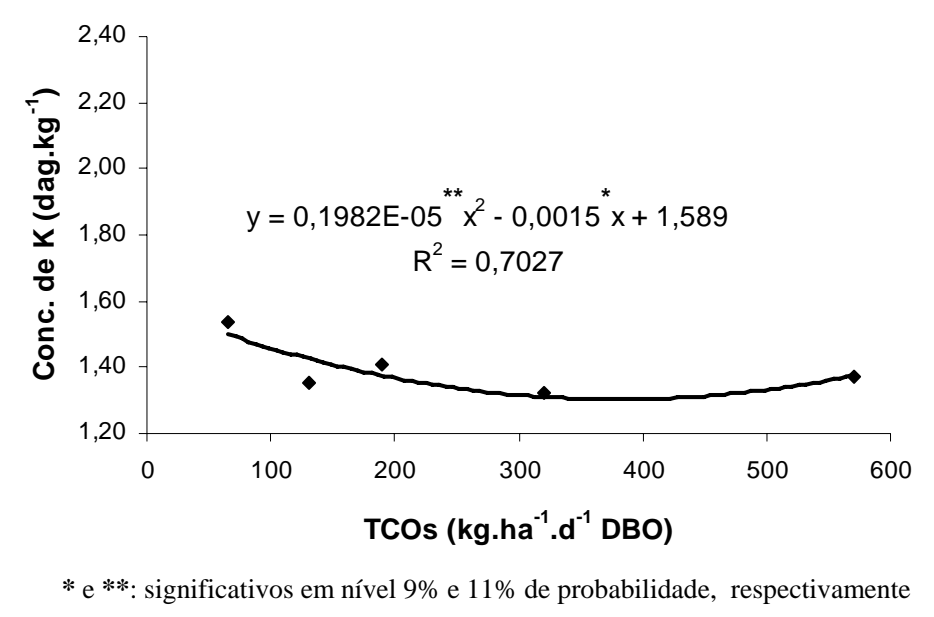

Figura 5. Variação da concentração de $K$ na parte aérea do capim tifton 85, em função das taxas de carga orgânica superficial (TCOs) aplicadas.

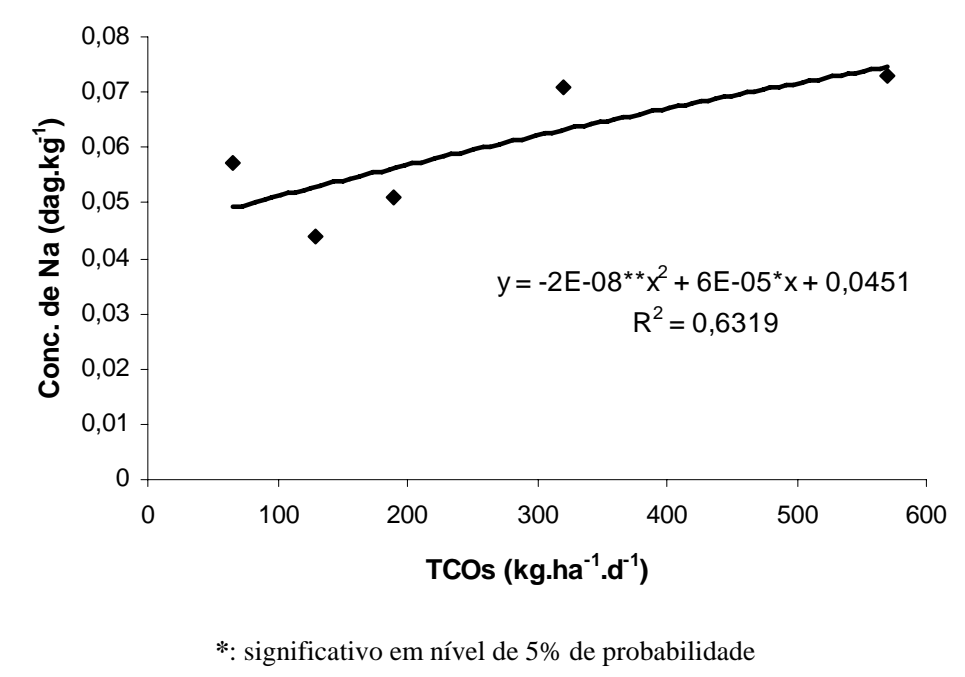

Figura 6. Variação da concentração de Na na parte aérea do capim tifton 85, em função das taxas de carga orgânica superficial (TCOs) aplicadas.

Oliveira (1999) verificou que os conteúdos de proteína bruta, P, K, Ca e Mg reduziram linearmente com a idade de rebrota do capim tifton 85 cultivado convencionalmente (adubação química mais irrigação), sendo de 15,60 e 4,50 dag. $\mathrm{kg}^{-1}$, 0,98 e 0,39 dag.kg-1, 3,97 e 1,28 dag. $\mathrm{kg}^{-1}, 0,56$ e 0,37 dag. $\mathrm{kg}^{-1}$ e 0,37 e 0,29 dag. $\mathrm{kg}^{-1}$, aos 14 e 70 dias de idade, respectivamente. Os conteúdos de proteína bruta obtidos neste trabalho ficaram na faixa de 18 a 25 dag. $\mathrm{kg}^{-1}$, valores muito superiores aos obtidos por Oliveira (1999) no capim tifton 85, aos 14 dias após a sua rebrota. No que se refere a $\mathrm{P}$ e K, os valores ficaram pouco acima dos obtidos pelo mesmo autor no capim tifton 85, aos 70 dias após a rebrota. Entretanto isso não é indicativo de deficiência desses nutrientes na ARL, tendo em vista que o corte foi efetuado aos 45 dias, tempo mais próximo dos 70 dias do que dos 14 dias após a rebrota do capim.

Na Tabela 2 estão apresentados os valores de remoção de N-total, P-total, K e Na pelas plantas, em função das TCOs aplicadas em cada tratamento, calculados utilizando-se os 
valores de concentração média de $\mathrm{N}, \mathrm{P}, \mathrm{K}$ e Na obtidos no segundo corte e de produtividade do capim no período de cultivo (19/08 a 09/12).

Tabela 2. Valores de remoção de N, P, K e Na pelo capim tifton 85 em função das taxas de carga orgânica superficial (TCOs) aplicadas.

\begin{tabular}{|c|c|c|c|c|}
\hline \multirow{2}{*}{ TCOs $\left(k \cdot h a^{-1} \cdot\right.$ dia $\left.^{-1}\right)$} & \multicolumn{4}{|c|}{ Remoção (kg.ha ${ }^{-1}$ ) } \\
\hline & $\mathbf{N}$ & $\mathbf{P}$ & $\mathbf{K}$ & $\overline{\mathrm{Na}}$ \\
\hline 66 & 216 & 24 & 115 & $\overline{4,3}$ \\
\hline 130 & 368 & 34 & 148 & 4,8 \\
\hline 190 & 421 & 41 & 148 & 5,4 \\
\hline 320 & 530 & 53 & 195 & 10,4 \\
\hline 570 & 544 & 61 & 204 & 10,9 \\
\hline Média & 416 & 43 & 162 & 7,2 \\
\hline
\end{tabular}

Considerando-se que os valores apresentados na Tabela 2 são relativos a apenas 112 dias de cultivo do capim, pode se considerar que os resultados obtidos sejam muito significativos, já que em um ano de cultivo nos SACs (mantendo-se mesmo intervalo entre cortes e constante a concentração dos elementos químicos no capim), a remoção de nutrientes pode

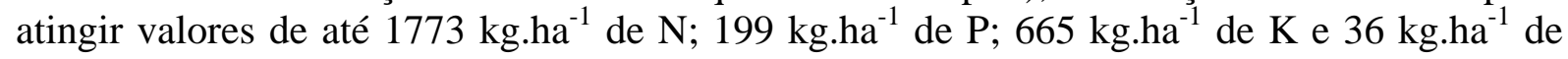
Na.

Tendo em vista que nas maiores TCOs aplicadas não houve problemas para o desenvolvimento do capim, tendo havido até aumento de produtividade, e que nessas condições houve maior remoção de nutrientes e sódio da ARL, pode-se afirmar que taxas de até $570 \mathrm{~kg} \cdot \mathrm{ha}^{-1} \cdot \mathrm{dia}^{-1}$ de DBO podem ser aplicadas visando-se obter eficiente tratamento dessa água residuária.

\section{CONCLUSÕES}

Com base nos resultados obtidos, pode-se concluir que:

- o capim tifton 85 se adaptou bem aos sistemas alagados construídos, com a aplicação da ARL, em TCOs de 66 a 570 kg.ha ${ }^{-1} \cdot \mathrm{dia}^{-1}$, com desenvolvimento axial e bom aprofundamento das raízes, não apresentando problemas fisiológicos ou nutricionais;

- o capim tifton 85 apresentou grande produtividade média de matéria seca e proteína bruta e relativamente grande capacidade de remover nutrientes e sódio da ARL, devendo ser considerado como opção para cultivo em SACs, caso se deseje a produção de forrageiras de grande valor nutricional para alimentação animal;

- TCOs de até $570 \mathrm{~kg} \cdot \mathrm{ha}^{-1}$.dia ${ }^{-1}$ de DBO podem ser aplicadas visando-se obter eficiente tratamento da água residuária de laticínios.

\section{REFERÊNCIAS BIBLIOGRÁFICAS}

BRASIL, M. S.; MATOS, A. T.; SOARES, A. A.; FERREIRA, P. A. Qualidade do efluente de sistemas alagados construídos, utilizados no tratamento de esgoto doméstico. Revista Brasileira de Engenharia Agrícola e Ambiental, Campina Grande, v.9, p. 133-137, 2005. 
BRASIL, M. S.; MATOS, A. T.; SOARES, A. A. Plantio e desempenho fenológico da taboa (Thypha sp.) utilizada no tratamento de esgoto doméstico em sistema alagado construído. Engenharia Sanitária e Ambiental, Rio de Janeiro, v.12, p. 266-272, 2007.

CAMPOS, J. C.; FERREIRA, J. A.; MANNARINO, C. F.; SILVA, H. R.; BORBA, S. M. P. Tratamento do chorume do aterro sanitário de Piraí (RJ) utilizando wetland. In: SIMPÓSIO ÍTALO-BRASILEIRO DE ENGENHARIA SANITÁRIA, 6., 2002, Vitória. Anais... Vitória: ABES, 2002. 1 CD-ROM.

CECATO, U.; BORTOLO, M. Importância econômica das espécies forrageiras na produção animal. Gênero Cynodon. In: II Curso de Produção e Utilização de Pastagens Módulo I. Maringá: CPAF, 1999. p.15-20.

GOMIDE, J. A. Adubação fosfatada e potássica de plantas forrageiras. In: PEIXOTO, A. M.; MOURA, J. C.; FARIA, V. P. (eds.). Pastagens: fundamentos da exploração racional. Piracicaba: FEALQ, 1986. p.155-164.

HUSSAR, G. J. Avaliação do desempenho de leitos cultivados no tratamento de águas residuárias de suinocultura. 2001, 118f. Dissertação (Mestrado em Engenharia Agrícola) - FEAGRI-UNICAMP, Campinas, 2001.

KIEHL, E. J. Fertilizantes orgânicos. São Paulo: Ceres, 1985, 492p.

NOGUEIRA, S. F. Balanço de nutrientes e avaliação de parâmetros biogeoquímicos em áreas alagadas construídas para o tratamento de esgoto, 2003, 137f. Dissertação (Mestrado em Energia na Agricultura) - Centro de Energia Nuclear na Agricultura, Piracicaba, 2003.

OLIVEIRA, M. A. Morfogênese, análise de crescimento e valor nutritivo do capim-tifton 85 (Cynodon ssp) em diferentes idades de rebrota, 1999, 94f. Dissertação (Mestrado em Zootecnia) - DZO/Universidade Federal de Viçosa, Viçosa, 1999.

PAGANINI, W. S. Disposição de esgotos no solo (Escoamento à superfície). São Paulo: AESABESP, 1997. 232p.

POSTIGLIONI, S. R.; Messias, D. C. Potencial forrageiro de quatro cultivares do gênero Cynodon na região de Campos Gerais do Paraná. In: REUNIÃO ANUAL DA SOCIEDADE BRASILEIRA DE ZOOTECNIA. 35., 1998, Botucatu. Anais... Botucatu: SBZ, 1998. p.439-441.

QUEIROZ, F. M. Avaliação de gramíneas forrageiras para o tratamento de águas residuárias da suinocultura. 2000, 91f. Dissertação (Mestrado em Engenharia Agrícola) - DEA/Universidade Federal de Viçosa, Viçosa, 2000.

QUEIROZ, F. M.; MATOS, A. T.; PEREIRA, O. G.; OLIVEIRA, R. A.; LEMOS, A. F. Características químicas do solo e absorção de nutrientes por gramíneas em rampas de tratamento de águas residuárias da suinocultura. Engenharia na Agricultura, Viçosa, v.12, n.2, p. 77-90, 2004. 
SEZERINO, P. H.; PHILIPPI, L. S. Filtro plantado com macrófítas (Wetlands) como tratamento de esgotos em unidades residenciais - Critérios para dimensionamento. In: CONGRESSO BRASILEIRO DE ENGENHARIA SANITÁRIA E AMBIENTAL. 22., 2003, Joinville. Anais... Joinville: ABES/AIDIS, 2003. 1 CD-ROM.

SILVA, D. J. Análise de alimentos (métodos químicos e biológicos). 2.ed. Viçosa: Imprensa Universitária, UFV, 1998. 165p.

SOUSA, J. T.; VAN HAANDEL, A. C.; COSENTINO, P. R. S.; GUIMARÃES, A. V. A. Pós-tratamento de efluente de reator UASB utilizando sistemas "wetlands" construídos. Revista Brasileira de Engenharia Agrícola e Ambiental, Campina Grande, v.4, n.1, p.87-91, 2000.

STEFANUTTI, R.; MATTIAZZO, M. E.; CORAUCCI FILHO, B.; NOUR, E. A. A.; FIGUEIREDO, R. F. Comportamento de duas forrageiras sob diferentes taxas de aplicação de esgotos sanitários utilizando o método do escoamento superficial. In: CONGRESSO BRASILEIRO DE ENGENHARIA AGRÍCOLA. 28., 1999, Pelotas. Anais... Pelotas: UFPEL, 1999. 1 CD-Rom.

VALENTIM, M. A. A. Desempenho de leitos cultivados (“construted wetland") para tratamento de esgoto: contribuições para concepção e operação. 2003, 210f. Tese (Doutorado em Engenharia Agrícola) - FEAGRI - Faculdade de Engenharia Agrícola/UNICAMP, Campinas, 2003.

VARGAS, R. M. E.; MEURER, E. J.; ANGHINONI, I. Mecanismos de suprimento de fósforo, potássio, cálcio e magnésio às raízes de milho em solos do Rio Grande do Sul. Revista Brasileira de Ciência do Solo, Viçosa, v.7, p. 143-148, 1983. 